\title{
A local government authority leading action research: Impacts and replicability
}

\author{
Commonwealth Journal of Local Governance \\ Special Issue March 2010: \\ Commonwealth Local Government Conference \\ Freeport, Bahamas, May 2009 \\ http:/lepress.lib.uts.edu.au/ojs/index.php/cjlg
}

\section{Neranjana Gunetilleke ${ }^{1}$}

Centre for Poverty Analysis

\begin{abstract}
This paper explores whether the approach taken by the Colombo Focus City project has had an impact on overcoming urban challenges through research-based learning designed to influence the policy and implementation processes of local government. The Colombo project, initiated and led by the Colombo Municipal Council, offers a model and strategies that offer insights into how action research might influence policy and practice at the local level. The model is one where the policy-makers - or more accurately, policy advisors and interpreters - lead the research team and are part of the implementation stages and learning processes. The paper also considers how the nature of this particular local government authority influenced the potential for policy change. Finally, it draws out factors that can be considered critical in replication of this model of research influencing policy. ${ }^{2}$
\end{abstract}

Keywords: Sri Lanka, Local government, Policy influence, Action research.

\footnotetext{
${ }^{1}$ The author wishers to thank all members of the Colombo Focus City Project, particularly Azra Abdul Cader, MHU Chularatne, Kumudhini Samarasinghe, and Mark Redwood of IDRC for comments on the original Working Paper. Special thanks to M.H.U. Chularatne for presenting the paper at the Commonwealth Local Government Forum, Research Colloquium at Freeport, Bahamas, May 2009 on behalf of the author, and to colleagues at the Centre for Poverty Analysis (CEPA) who contributed extensively to developing the ideas set out in this paper. The author may be contacted via CEPA at www.cepa.lk

${ }^{2}$ The following is a direct link to the Colombo City Focus work: http://www.idrc.ca/en/ev103124-201-1-DO_TOPIC.html
} 


\section{Introduction}

The Focus City (FC) research initiative comprises action research projects in eight cities that seek to promote in-depth research and allow time to successfully monitor outcomes. ${ }^{1}$ The initiative is funded through the Urban Poverty and Environment Programme of Canada's International Development Research Centre (IDRC). The Colombo Focus City Project, titled Community-based Assessment and Improvement of Living Environment in Underserved Settlements and the Environs: The case of Gothamipura-Colombo, sought to reduce environmental burdens that contribute to poverty in 'underserved settlements' (USS) by strengthening the capacity of people to better access basic urban services, reduce environmental pollution and lessen vulnerability to natural disasters. The Colombo project had the following specific objectives:

- Using water and sanitation (focusing on sewerage) as an entry-point, to develop a model of participatory service provision that addresses how best to deliver different types of urban services.

- To improve upon knowledge of the link between poverty as expressed through financial, socio-political, resource and human assets, and environmental burdens (flooding, health issues, poor sanitation affected by the lack of proper sewerage).

- To assess how improved access to services contributes to an improved sense of land tenure security.

- To use an integrated model in order to improve on other Colombo Municipal Council initiatives and policies related to urban service provision and poverty reduction in USS.

- To enhance team capability in doing participatory research and communication through involvement in a learning network with other Focus City teams and in the community.

The project involved four interventions in order to meet these objectives:

- Constructing a sewer system for Gothamipura

- Improving the solid waste disposal system

- Strengthening the capacity of the local Community Development Council

- Developing a USS policy document for improved service provision. 


\section{Integrating learning and evidence into policy-making and implementation}

The research community's conviction of the worth of their knowledge to policy makers and implementers has not always been shared by those groups, but this is slowly changing. ${ }^{3}$ As these groups are becoming more open, researchers are engaging in bridging the gap between research knowledge, the production of evidence, and the particular demands of policy-making and implementation. A body of literature has developed around this theme, led mainly by development research institutions such as the Overseas Development Institute (ODI), the International Development Research Centre (IDRC), and the Institute of Development Studies (IDS). ${ }^{4}$ The debate has been taken up by networking forums, ${ }^{5}$ and case studies are used extensively in an effort to understand the success and failures in different contexts and the move towards best practice. ${ }^{6} \mathrm{~A}$ fundamental lesson has been recognition of the need to facilitate the process of linking research/evidence to policy-making/makers. According to the ODI's Research and Policy in Development (RAPID) framework, research can successfully influence policy when the information provided is credible (evidence), appropriately communicated (links), and the environment is ready for change (political context). ${ }^{7}$ This framework reflects the general trend in the literature which is oriented either towards sensitizing policy makers regarding the value of research, or towards researchers increasing their understanding of the policy context. The latter approach advocates using policy analysis frameworks to understand the context, and using that understanding when research is first conceived and later disseminated. ${ }^{8}$ The former highlights ideas about greater inclusion of policy makers and implementers in the research process. This can lead to greater usage of research, increased ownership and 'buy in' - critical to the absorption of research learning into policy-making. Increased understanding of the factors involved has highlighted opportunities and strategies to bridge the gap between research and policy. Strategies include: research themes and questions being influenced by an understanding of the

\footnotetext{
3 See work by P. Davies: Is evidence-based government possible? Policy Evaluation in the United Kingdom, and G. Banks, Evidence based policy making: What is it? How do we get it? Australian Government Productivity Commission, ANZSOG/ANU Public Lecture Series 2009, Canberra.

4 See also the following ODI and IDS associated links: http://www.eldis.org; http://www.odi.org.uk/Rapid; http://www.ebpdn.org/index.php

5 Ibid. See http://www.who.int/rpc/evipnet/en

${ }^{6}$ See for example J. Court (ed.), Bridging Research and Policy Development: Evidence and the Process of Change, ITDG 2005; G. Yaron and Louise Shaxson, Good Practice in Evidence Informed Policy: An initial review for DFID, 2008.

7 See http://www.odi.org.uk/RAPID/Projects/R0166/Docs/RAPID_framework_HIV.pdf

8 W.Gill, 'How far does research influence policy?' European Journal of Public Health, 4, 1994, pp. 233-235.
} 
policy environment, agendas of key players and negotiation spaces; targeting 'champions' (policy makers in key positions who will be influential change agents); building trust between research providers and users; placing academics/researchers on 'advisory boards' for policy- making; 'proving' using high quality research; and presenting a combination of existing/accepted knowledge and new knowledge. Communicating research findings to policy-makers has also become a core activity, involving strategies such as making research findings less technical, linking them to priority problems (with summarized credible evidence), and research designed specifically to translate evidence into policy. ${ }^{9}$

In this paper we present a model that adds to the portfolio of strategies of research influencing policy and practice. Using the experience of the Colombo FC action research project (initiated and led by the city's local government authority - the Colombo Municipal Council), we consider a case where the policy makers, or more accurately, the policy advisors and interpreters, led the research team and were very much part of the implementation and learning processes. Exploration of this approach has been facilitated by in-process monitoring which required and enabled the action research team to target itself as a subject of study. Initial analysis has shown that the implications of this institutional arrangement can be considered from two points of view: that of the local government or service provider, and that of researchers. For the local government/service provider, the main new learning is in the area of alternative sources of funding for sustainable development of underserved settlements. The main lesson for researchers is about their impact on the policy process, and scaling-up project learning via absorption by key stakeholders. This paper focuses on the latter.

\section{The Colombo model}

The institutional model of the Colombo Focus City project was deceptively simple, and at first glance it involves little that has not been tried out before in Colombo or in other cities around the world. The institutional arrangement was based on a partnership approach that brought together groups that are perceived as the main stakeholders for improving the living environment of the Gothamipura USS. ${ }^{10}$ Those stakeholders were

\footnotetext{
9 Yaron, Gil and Louise Shaxson, 2008, Good practice in evidence informed policy: an initial review for DFID.

${ }^{10}$ Colombo city has 1,614 USS within its municipal limits, within which live approximately $50 \%$ of Colombo's population. While the USS have very high population density (approximately 820
} 
the Colombo Municipal Council (CMC) as the regulatory authority and the service provider, and the Gothamipura Community Development Council (CDC) as the direct beneficiaries. In addition, as required in an action research project, a research institution, the Centre for Poverty Analysis (CEPA) and a non-government organisation (NGO) specialising in urban development (Sevanatha), completed the partnership, along with the research advisor and funding provider, IDRC. The unique element of this model, however, is that the action research project initiator and leader was the local government authority, the CMC. Action research most commonly germinates in traditional research spaces such as universities and independent research institutions. In water and sanitation research, the researcher will look to developing partnerships with an implementing organization, community and local authority. The nature of the partnership, including the role played by each partner, is often determined by balancing the research agenda with the 'on the ground' realities of institutional interests and capacities. The norm, however, is for the research project to be led by a research institution or NGO, and for the local authority to play an implementation role.

In the case of the Colombo FC the role of the local authority was markedly different. It was the CMC that: identified the potential project; selected Gothamipura as the beneficiary community; invited Sevanatha and CEPA as study partners; initiated the work; and provided leadership in preparing and submitting the research bid to IDRC. Once the proposal was accepted, the institutional model that was confirmed for the action research project was that of the $\mathrm{CMC}$ as project leader, undertaking overall coordination and management, and with specific departments within the CMC having planning and implementation responsibilities for the action elements of the research. Sevanatha's role included community mobilization and implementation of additional projects identified by community action plans (CAP), while CEPA had specific research and monitoring and evaluation (M\&E) responsibilities. The Gothamipura community (represented by the CDC) had the key responsibility of identifying community priorities, coordinating community input and implementation of construction of sewer lines, and other action components of the project. The IDRC was the funding partner and provided inputs to both research and monitoring and evaluation. The following discussion will explore how this institutional model helped increase the local government authority's (LGA) 
ownership of the project, and the implications of this increased ownership. Ownership by the community as the key complementary stakeholder is also considered briefly.

\section{Enhancing ownership}

'Ownership by key stakeholders', 'strategies to increase ownership,' and 'project failure due to lack of ownership’ are phrases that appear in many evaluation reports as well as in the discourse on creating evidence-based policy making or greater usage of research learning by targeted stakeholders. The following discussion identifies some key factors that drive ownership, its impact on implementation and sustainability of the project, and the potential for policy influence, especially via the bureaucracy which is directly involved in policy advice, interpretation and implementation. In the case of Colombo, three main factors are identified as influencing LGA ownership and its implications: (1) integration into CMC strategies and plans for the city; (2) having an 'action' component of the research that can provide sufficient resources to make a critical difference in a priority intervention; and (3) integration into the CMC institutional framework.

\section{Integration into the CMC plan for the city}

The approach adopted for the research was aligned to the principles of the Colombo City Poverty Reduction Strategy (PRS), and more importantly, included a specific intervention relevant to the CMC's plan for the city. It maintained this focus throughout the project planning and implementation phases. CMC was able to ensure the continued relevance of the project as it led the research and could negotiate directly with the funders. In most other projects, where the LGA is not the team leader, the competing priorities of the project leaders and the LGA have to be negotiated, often resulting in interventions that are not necessarily a priority of the LGA and undermining ownership. At the level of strategic policy orientation, the 2004 Colombo PRS identifies as priorities 'equitable distribution of basic amenities among all the citizens' and 'effective delivery of municipal services across the city and among all its citizens'. The action research bid that was put in by the LGA was directly in line with these overall priorities for the city. In addition, the methodology of the action research - based on a partnership approach with the community as key stakeholder - aligned with the CMC's principles governing the PRS, which include:

- Principle A: Responsive to community needs and aimed at tackling the causes and consequences of poverty. 
- Principle B: Relies on beneficiary participation in planning, implementation, monitoring and sustaining the systems.

- Principle D: Promotes sustainable partnerships in which resources, responsibilities and risks are shared among the key stakeholders.

- Principle H: Relies on genuine community empowerment where resources, functions, and responsibilities are shared between the urban poor and the Municipality (CMC, 2004:4).

While alignment with the strategic orientation of CMC policy documents was a key factor in LGA ownership, the project's focus on more micro-level (and hence realizable) priorities also played a significant role. Improving sewerage facilities, particularly in flood prone areas, is a priority development target of the CMC. Lack of sewer lines in specific areas has been identified by the CMC as creating bottlenecks to the development of USS, and the clearing of these bottlenecks is the basis for the CMC's incremental approach to broader upgrading of those settlements. Hence a critical element of the Colombo FC project has been the early identification of a specific intervention (primarily the construction of the sewer line) in a specific location (Gothamipura USS), and a continued focus on that priority. This focus was identified and maintained in its original form from the project proposal stage onwards. In-process monitoring strongly indicated that the LGA as project initiator and leader (and its officers) had a strong commitment towards ensuring this operational focus, while also providing space for the research orientation. $^{11}$

\section{Providing sufficient resources to make a difference}

The challenges facing city governments in funding the development and maintenance of pro-poor utilities are discussed extensively in global fora. ${ }^{12}$ The Colombo City is no exception where revenue and regulatory constraints leave very little resources for capital expenditure in USS. The CMC has in the past experimented with many sources of funding and resource generation to meet these needs, but current allocations amount to only some Rs.50,000 per USS per annum. This does not allow for spending a substantial

11 Project completion impact evaluation advisory input was provided by CEPA to the CMC/GTZ PRIMUSS project (unpublished source), and Colombo FC in-process monitoring KPI data (unpublished source).

12 For example, see Financing for Cities and the Urban Poor, see http://www.citiesalliance.org and 'Financing Local Government' in Improving Local Government: The Commonwealth vision, background discussion paper for the Commonwealth Local Government Conference, Freeport, Grand Bahama, 11-14 May 2009, by Dr Philip Amis 
amount on a single intervention in a particular USS. The cost of developing the sewer line in Gothamipura exceeded Rs.20m (about USD $0.18 \mathrm{~m}$ ) ${ }^{13}$ and was far out of the range of existing CMC budgets for development within a single USS. However, the funding and resources made available for the Colombo action research allowed not just the construction of the sewer line but also complementary holistic upgrading of the community's physical space. Such access to resources which enable critical changes to be made in areas prioritised by the LGA hade a very direct impact on ownership and thereby on implementation and sustainability of the intervention as it was incorporated into the main CMC system.

\section{Integration with the CMC institutional structure}

Since it was the project leader, project management and implementation was and continues to be embedded in the institutional structure of the CMC through its Professional Services Department. This department is the organisation's central point for all externally funded special projects, and it prepared the proposal for the IDRC Focus City programme. The project was structured accordingly:

- the Project Leader was the head of the department and the coordinating officer was attached to the same

- the project implementation teams were drawn from the relevant implementation departments within the LGA such as the Engineering Department and Solid Waste Management Department

- the Steering Committee was aligned to the LGA management structure and headed by the Municipal Commissioner. ${ }^{14}$

Unlike most other externally funded research or implementation projects, there was no separately located project office, nor were there any non-national 'experts' or project members. The project partners Sevanatha, CEPA and the Gothamipura CDC all provided input from within their own institutional structures. The funding partner, IDRC, does not maintain a national presence in Sri Lanka, and provides inputs from its home base. This integration of the project in the CMC institutional structure further influenced ownership.

\footnotetext{
13 Project cost benefit data collection, 2007 (unpublished source).

14 The Municipal Commissioner is the most senior position of the officials in the governing body of the Municipal Council.
} 


\section{Impact of increased ownership}

As the project was implemented, in-process monitoring highlighted the implications of high level of ownership by the key stakeholder, the LGA.

- Presence and active participation of all levels of LGA officers was extremely high.

This is in contrast to the levels of participation noted in evaluation reports of externally facilitated pilot projects where ensuring active participation of key implementing partners can be a challenge. In-process monitoring clearly indicated that the LGA as well as all stakeholders involved, including the Gothamipura community, saw the project as a 'CMC project' rather than ' $\mathrm{x}$ institution's' as is common in externally funded projects with more visible and separate project offices.

- Decision making and problem solving was led by the LGA, with a resulting acceptance of responsibility for implementation. The external partners (CEPA and Sevanatha) were very closely involved in the discussions and decision process, however as the leader of the project the LGA assumed responsibility for project management and implementation of the intervention. This had a direct impact on the research-based intervention entering the mainstream CMC system, thereby increasing its potential sustainability.

- $\quad$ The FC team was able to attract good participation from other state institutions and officials (resource providers and implementers). For the ancillary interventions of the project such as securing land deeds, urban agriculture, reconstructing the community hall, the project team worked in close association with senior state sector officials as well as private service providers such as surveyors. Access to these stakeholders was facilitated by the legitimacy of a project led by the LGA as well as by the existing networks of both CMC and Sevanatha that include high level officers of parallel state agencies.

- Securing active participation and buy in of the community. This is a critical issue faced by all interventions that are carried out with any degree of stakeholder orientation. Participation and acceptance of the project by the community is particularly important within the USS context, not only due to the participatory design of the project, but also to address socio-political structures that can potentially disrupt project implementation. Despite the sewer line being a strongly felt need, the community was skeptical that the actual intervention would take place. However, this attitude changed as the implementation of the 
sewer line as well as other project activities commenced and progressed. The community's trust in the project as well as in the LGA increased substantially, which has had a positive impact on both project implementation and the community's longer-term relationship with the CMC as a key service provider.

- Accountability of project management. Accountability to the partner community was built into the design of the Colombo Focus City along the same lines as most action research and development projects. However, the Colombo institutional model demonstrated two additional forms of accountability due to its integration into the LGA structure:

1) Being answerable to elected representatives of the people (as all officers of the CMC are directly accountable to the council). At the early stages of the project questions were raised by the elected members regarding the selection process of the partner USS Gothamipura, as well as the partner institutions CEPA and Sevanatha. The project obtained council approval to proceed only after satisfactory explanations were provided, thus illustrating the functioning of a democratic accountability mechanism that is often under-recognised in development projects.

2) Being accountable to the national legal framework, as the CMC had to get prior approval to provide services to housing zones that were not in line with city building regulations. ${ }^{15}$ Such legal clearance was obtained prior to the project proposal being submitted.

In summary, the high-level and direct involvement by the key stakeholder institution, the LGA, plus a large group of its officers, created a participatory learning environment. The research work and project learnings of the Colombo FC team and research partners have had immediate resonance with the implementers and decision-makers. The positive outcome of this participatory work has meant that extensive strategizing of activities to internalize learning has not been required. For example, observations of the research partners were discussed and debated at partner meetings and at monitoring and evaluation meetings prior to the production of research papers. Hence, while the LGA decision makers and implementers may not in fact have read the research papers, they had already provided input to - and become familiar with - the discussion of issues raised and learning outcomes.

15 The Slum and Shanty Development Programme (1978) relaxed urban planning regulations in designated areas and termed them Underserved Settlements. 


\section{Creating conditions to influence procedure and policy}

The challenge of feeding-in evidence to policy-makers and the process of policy-making, is one of most dynamic topics of discussion among the research community. This section considers how the scope for research to influence policy can increase when the research project is led by the LGA, which is also the policy-maker and implementer. The proposal prepared by the LGA-led team and presented to the IDRC included a specific objective to “...improve on previous CMC initiatives and policies related to urban service provision and poverty reduction in USS." ${ }^{16}$ However, it was at the design stage of the study's monitoring and evaluation plan that the implications of the LGA-led institutional model on policy influence were more fully realised and discussed. The planning sessions identified the high potential of influencing LGA policies (formally and informally) from within the system as a distinct advantage in meeting the policy change objective. CMC team members who had an extensive understanding of the realities of the policy-making process within the LGA, including the challenges and space available for changes in policy, were seen as a distinct resource that should be capitalized upon. ${ }^{17}$ Two groups were identified by the project team as key players in policy-making and implementation: elected council members (MMCs) who are the policy makers, and the LGA bureaucracy which advises these policy-makers, interprets and implements policy.

\section{Municipal council members}

Despite knowledge of the vital role of the MMCs in directly investing in USS programs via their individual budget allocations, neither the design nor the implementation of the action research drew this group directly into the study. Also, potential spaces for direct inclusion such as steering committee membership were not opened up. Thus an opportunity for close contact that would have helped policy-makers internalise learning was lost. However, as the research study was embedded in the LGA through direct project leadership, approval of the council had to be obtained at all necessary points, and as noted previously, CMC officials remained accountable to the elected members. The unstable nature of the current council and the lack of experienced elected members were given as the reasons for minimizing the project's links with them. ${ }^{18}$ While

\footnotetext{
16 Project Proposal, Community Based Assessment and Improvement of Living Environment in USS and Environs, CMC 2007.

17 Outcome Challenge 2, Project M \& E Plan, 2008.

18 Council elections were held in 2006, and for the first time in 50 years the political party in power changed, primarily due to a technical electoral issue during nominations. The possibility of the council being dissolved was constantly a issue and a number of court cases followed. This
} 
acknowledging that these are legitimate issues, in-process monitoring of the project's policy influence has nonetheless identified this as a key area of weakness which may have benefited from greater effort and more creative thinking.

\section{Policy advisors and implementers}

The policy impact and broader internalizing of project learnings through the CMC bureaucracy has been substantially greater than in the case of elected members. It was specifically targeted and gradually showed results as the project progressed. Within the bureaucracy, the project team identified several layers of potential influence. The project cell, which comprised officers from the Professional Services Department, heads of three operational departments, Sevanatha and CEPA was seen as the group that would internalize the learning directly and be responsible for influencing other layers of influence. These included the implementing departments of CMC, the Municipal Commissioner and council, and government agencies such as the National Housing Development Authority, the National Water Supply and Drainage Board, and the Urban Development Authority.

- The Project Team. The direct access of CMC project team members to the high levels of CMC management was a distinct advantage in influencing policies and decisions. For example, the project leader and the leader of the implementation group were members of the six-person 'Apex Management' group of CMC by virtue of their office - Deputy Commissioner (Professional Services) and Deputy Commissioner (Engineering). Also, the design and implementation of the action component of the research (construction of the sewer lines, solid waste management, land deeds, urban agriculture) directly involved the implementing departments of the CMC as well as the senior level officers of other government agencies. The direct participation of a critical mass of senior level officers in study initiation, planning and implementation has been a further key factor in internalizing learning and, potentially, influencing institutional policy and interpretation. Because implementing officers were drawn from the CMC permanent staff they have contributed both via their pre-existing knowledge, and by continuing to facilitate the institutionalization of the project learnings within the LGA. An important outcome of this has been a more efficient bureaucratic

situation is not the norm in the CMC, where previously the Mayor and council had run their full terms. 
process: there was less need to establish the importance for policy change amongst decision-making officers (including the process and causes), and it was easier to communicate with them on the issues involved. Thus the credibility of the project and evidence base could be established through an on-going process in which the relevant officials were active participants.

- The Steering Committee. As noted earlier, the Colombo Focus City Steering Committee is headed by the Municipal Commissioner with all relevant CMC department heads as members. Those who make up this committee are the senior officers that would in other studies likely be targeted in an effort to influence policy from the 'outside'. In Colombo, the established level of trust, knowledge of each other as colleagues, and familiar working arrangements has enabled faster and greater absorption of new ideas into other activities of the LGA. See below for an example.

Edited extract from Colombo Focus City Process Monitoring Report, April 2009

\section{Outcome Challenge - the Local Authority:}

The local authority will use the learning from the piloted participatory integrated model to influence policy on service provision and poverty requction in USS.

Due to the structure of the Focus City $(\mathrm{FC})$ project which includes the main $\mathrm{CMC}$ decision makers, some infiltration of ideas and opportunities from the FC activities and Gothamipura community into broader CMC operations has been observed. For example, reporting on the FC activities at the Steering Committee, which is chaired by the Municipal Commissioner, led to discussions on the possibility of applying the following two project approaches elsewhere in CMC.

- The method followed in obtaining land deeds for the households in Gothamipura was discussed as a possible model to be used in other USS which had the prerequisites for land deeds being issued. It was accepted that the existing state mechanism, though cheaper for the people, was very time consuming. If the Gothamipura project found that the people were willing to contribute more towards the cost, this quicker approach could be used as a model.

- Consideration of urban agriculture activities led to a discussion on the possibility of the Gothamipura community taking on the model urban agriculture plot of the $\mathrm{CMC}$ at Viharamahadevi Park. The option of making a payment either to the Community Development Council or individuals for taking on the activity on behalf of the City was discussed.

At the steering committee meetings it was observed that the Municipal Commissioner engages actively with not only the implementation aspects of the FC project but also the potential learning. There is keenness to see how the project learning could benefit other USS and the City. 
- Parallel agencies and the 'Capital City' effect. Service provision and development in underserved settlements require cooperation with a number of Colombo-based national agencies such as the National Housing Development Authority (NHDA), the Water Supply and Drainage Board (WSDB), and the Urban Development Authority (UDA). The Colombo FC project has worked directly with the NHDA and WSDB in its planning and implementation of the sewer system, land titling and other interventions. Benefits for these agencies from this working relationship have been learning outcomes including: the amount the community is willing to pay to obtain prioritised services such as sewer line and land deeds; the impact of incremental change; and the role of partnership approaches. Because the CMC project team members were senior officers, staff of the other agencies interacting with the Colombo FC also tended to be officers at decision-making levels. This created an added benefit of a direct channel to feed lessons learned from the action research into these partner agencies. Also, given the national outreach of these agencies any learning absorbed by them could potentially influence decision-making and activities in other urban areas. Similarly, given that the CMC is the oldest and largest municipal council in Sri Lanka, as well as that of the capital city, other municipal councils and organizations involved in urban service delivery look to its experiences. ${ }^{19}$ However, it is still too early to identify any solid evidence for this spread effect of learning.

\section{Influencing the wider development agenda}

A second element of policy influence arises from the role of IDRC as the funding and global research partner. The Colombo FC project is part of an eight-city global research initiative with shared learning and policy influencing objectives. ${ }^{20}$ Having a well networked international partner focused on linking research to policy has meant that the learnings of the Colombo FC project can contribute to the global debate on policy influence. This opportunity would have been more limited had it been purely a national study. A particular benefit of this broader dissemination of learning is when studies reveal results that in some cases challenge the status quo in development practice. Specifically, the lesson from the Colombo FC project of the potentially positive impacts

\footnotetext{
19 E.g. Solid waste disposal, urban greening and composting was tried in Kurunagala, Badulla.

20 See www.idrc.ca/en/ev-81920-201-1-DO_TOPIC.html
} 
of LGA-led action research and implementation is in contrast to the widely adopted approach of giving leadership to research institutions, community-based or nongovernment organizations, or the private sector.

\section{Potential for replication of the model}

A core element of a 'model' is its potential for replication. The way in which the institutional model used in the Colombo FC project was developed and functions provides some indicators for its replicability. This would require at least some of the following features to be present in the key partners.

- The CMC's pro-poor orientation. The CMC's focus on improving the quality of services and access to sanitation within the USS reflects a strong pro-poor orientation. The regulatory role of CMC could create a challenge to service provision to the USS, as their location and development are in breach of regulations relating to building, tax, hygiene etc. In addition, the line between public property and private ownership is blurred within USS, potentially creating further constraints to developing and maintaining services and utilities. However, the pro-poor orientation of the LGA, derived to a large extent from the welfare orientation of the Sri Lankan state, has led it to continuously explore methods of service delivery to the USS. Unlike many other large cities in the world, where the poor live in segregated enclaves with little access to the services and investments of the 'formal City', the relatively small size and integrated nature of USS in Colombo has enabled their residents to access free education and health care, fuel subsidies etc. provided by the central government. In addition, USS residents are prime beneficiaries of the various welfare services offered by the CMC exclusively to the citizens of Colombo such as good quality and welllocated health care services, playgrounds and recreation spaces, grants for students and for households during times of crisis (for example funerals and natural disasters), and vocational training. Financing the development of USS has, however, remained a challenge as these locations generate no revenue to the LGA in terms of taxes or other service fees. In addition, there are few specific budgetary allocations for improvements to USS. This situation has led to some very innovative financial and institutional experiments by the CMC, of which the Colombo FC project is one of the more successful examples. 
- Institutional flexibility of the funding partner: The strong orientation of the IDRC towards linking research to policy (IDRC, Corporate Strategy 2005-2010) has complemented the CMC's effort to move into a non-conventional area of action research as a means of improving services to the underserved communities of Colombo. IDRC's call for proposals for the global FC project only required a partnership approach; it did not state how or where project leadership should be formed. This created the space for the CMC to initiate the bid itself. In fact, IDRC has two projects within the broader Focus City project (including Colombo) that are led by a LGA partner. This reflects a deliberate plan to have a balanced portfolio of lead partners (international organisations, local governments and research institutions), and to generate a range of learning opportunities. Despite the realization that working on research projects with local governments can be highly risky, the growing body of evidence that research is best guided by its users has led the IDRC to experiment with LGA leadership in its action research. ${ }^{21}$ Importantly, the institutional orientation of the IDRC, which embodies neither a totally research orientation (that would have led to partnering research institutions), nor a conventional bi-lateral model (that would favour working with a state ministry), allowed the combination of research and a LGA as lead partner.

Factors that prompted the IDRC prior to accept the experimental institutional arrangement put forward by the CMC included the unusually positive welfare orientation of the LGA; the openness of the CMC to new institutional forms as illustrated by the role of its Institutional Development Centre (see Box 2); the potential for partners CEPA and Sevanatha to fill the research and participatory gaps as required; and the scope for significant policy influence and scaling-up in a city the size of Colombo. ${ }^{22}$

- Familiar working partners. CMC's decision to partner with known institutions and the community was influenced by the need to reduce the external risks that would impact on project implementation and possibly failure. This was considered particularly important as the action research was seen as a pilot project, where the learning would enable scaling-up to other USS. All three partners were identified by the CMC based on previous working relationships.

${ }^{21}$ Process monitoring interview, IDRC Project Manager (unpublished source).

22 Process monitoring interview, IDRC Project Manager (unpublished source). 
Sevanatha and CEPA brought exceptional skills in urban mobilization and research. Both organisations had a strong Colombo base and experience in working at the community level as well as with government agencies and global research institutions. The Gothamipura CDC was one of the most experienced in project participation among the USS of Colombo.

\section{Learning and summary}

The scheduled date of completion of the Colombo FC action research was the end of 2009. An evaluation of its impact will take place after a time lag of at least six months following the construction of the sewer lines and end of other project activities. However, many impacts and implications of the research design and implementation can already be observed and studied. CEPA and Sevanatha have studied the institutional arrangement of the Colombo FC team and the role of LGA leadership. They have been able to observe the internal workings of the team very closely while maintaining sufficient objective distance as researchers. This dual role created the space to discuss initial thoughts regarding the institutional structure and its implications with the LGA members of the team. The extensive experience of CEPA and Sevanatha in development research, externally funded implementation projects, academic debates on institutional forms, and evidence-based policy-making, brought a capacity to the FC team that enabled both a degree of reflection and comparisons with other situations where they have either been a partner or evaluated a project as researchers. Their observations of the Colombo FC indicate clearly that the project has benefited substantially from the LGAled institutional arrangement. Key factors were the focus on a specific intervention that is a critical priority (and in line with the LGA's plan for the city and USS), and that the project is embedded within the existing LGA institutional structure. The Colombo experience makes a strong case for using existing state structures to achieve the objective of increased ownership of action research and implementation, but, as discussed in the section on replicability, the correct conditions are critical for such a model to succeed in other contexts.

The role of community participation has not been a focus of this paper, as a great amount of knowledge already exists in relation to this issue. In addition, in-process monitoring of community participation in this project has shown a pattern very much in keeping with expectations based on past experience. A significant variation in this model, however, was that identification of priority interventions was based on the LGA's existing 
knowledge of needs and only verified via community participation. This resulted in a much shorter and simpler participatory process for selection and planning of project activities than is usually the case with externally funded development projects. The policy impacts of the project are still developing. The paper has discussed the findings of the in-process monitoring which point to a conducive environment for potential absorption, at least within the professional space. Lack of effort within the political space was justified by circumstances specific to the period under study. It would be useful, however, drawing from global learning and methods, to look more closely at the best ways to inform and influence the elected members of council.

\section{Bibliography:}

Amis, P. 2009, Improving Local Government: the Commonwealth vision, Background discussion paper for the Commonwealth Local Government Conference, Freeport, Grand Bahamas 1114 May 2009.

Asian Development Bank 2000, Sri Lanka Urban Development Sector Study.

Banks, G. 2009, Evidence based policy making: What is it? How do we get it?, Australian Government Productivity Commission, ANZSOG/ANU Public Lecture Series, Canberra, 4 February 2009.

Bastian, S., Gunatilleke, N., Jafferjee, A. and Weeratunge, N. 2005, Working Elephant or Perahera Elephant? An Ex-Post Evaluation of the Regional Rural Development Project (RRDP), Kandy, Centre for Poverty Analysis, Working Paper Series No. 4, February 2005.

Billand C. J. 2006, 'Expanding Local Government resources for capital projects through municipal borrowing and other market based financing', Global Urban Development, vol. 2, no. 1 .

Colombo Municipal Council 2005, 'Poverty Reduction Strategy for Colombo City (2004)', in J. Court (ed.), Bridging Research and Policy Development: Evidence and the process of Change, ITDG, 2005.

Centre for Poverty Analysis (CEPA) 2009, Colombo Focus City Process Monitoring Report, April 2009, CEPA.

Davies, P. 2004, Is Evidence-Based Government Possible?, Government Chief Social Researchers' Office, Prime Minister's Strategy Unit, Cabinet Office. London $<$ http://www.nationalschool.gov.uk/policyhub/downloads/JerryLeeLecture1202041.pdf>.

Evans, B., Mcmahon, J. and Caplan, K. 2004, The Partnership Paper chase: Structuring Partnership Agreements in Water and Sanitation in Low-Income Communities, (paper) Building Partnerships for Development, London. $<$ http://portals.wi.wur.nl/files/docs/msp/paperchase.pdf $>$.

Evans. B., Hutton, G. and Haller, L. 2004, Closing the Sanitation Gap - the Case for Better Public Funding of Sanitation and Hygiene, OECD background paper for the Round Table on Sustainable Development, 9-10 March 2004. $<$ http://www.oecd.org/dataoecd/35/48/39358569.pdf $>$.

German Foundation for World Population 2008, Budget Support Consequences for Sexual and Reproductive Health, German Foundation for World Population. $<$ http://www.euroresources.org $>$.

Gill, W. 1994, 'How far does research influence policy?', European Journal Of Public Health, vol. 4, no. 4, pp. 233-235. 
Gunetilleke, N. et al. 2004, Understanding the dimensions and dynamics of poverty in USS in Colombo, CEPA.

Hettiarachchi D. P., Legal Structure of Local Authorities in Sri Lanka, Municipal Councils, Urban Councils \& Pradeshiya Sabhas. Ministry of Local Government (Power point presentation).

International Development Research Centre (IDRC) 2005, Corporate Strategy and Program Framework 2005-2010, IDRC, Canada.

United Cities and Local Governments, Is Providing Budget Support to Developing Countries Effective? United Cities and Local Governments.

Param, L., Evans, B., Cardosi, J. and Hicks, N. 2005, Operational Guidance for World Bank Group Staff Rural Water Supply, Sanitation and Budget Support - Guidelines for Task Teams, The World Bank, September 2005.

$<$ http://siteresources.worldbank.org/INTWAT/Resources/46021141206643460526/RWSS_Budget_Support.pdf $>$.

Satterthwaite D. 2002, Local funds and their potential to allow donor agencies to support community development and poverty reduction in urban areas, Workshop report on Environment and Urbanization, April 2002, International Institute for Environment and Development. <http://eau.sagepub.com/cgi/content/abstract/14/1/179>.

Jayaratne, K. A. et al. 2002, Poverty Profile: City of Colombo: Urban Poverty Reduction through Community Empowerment, Report of DFID / UNDP / UN-HABITAT / UMP Urban Poverty Reduction Project, SEVANATHA, Colombo, February 2002.

$<$ http://www.ucl.ac.uk/dpuprojects/drivers_urb_change/urb_society/pdf_liveli_vulnera/Sevanatha_Poverty_Profile1.p $\underline{\mathrm{df}}>$.

UN-HABITAT, 'Sharpening the Global Development Agenda, Institutional and legal failure', in United Nations Human Settlements Programme 2003, The Challenge of Slums: Global Report on Human Settlements, United Nations Human Settlements Programme. < http://www.unhabitat.org/downloads/docs/GRHS.2003.1.pdf>.

Yaron, G. and Shaxson, L. 2008, Good practice in evidence informed policy: an initial review for DFID, Department for International Development, UK.

$<$ http://www.dfid.gov.uk/Documents/publications/research/good-practice-policyreview.pdf $>$. 